\title{
Neuronal control of localized inflammation through expressed nicotinic acetylcholine receptors: a study carried out in mice
}

\author{
M Thayabaran ${ }^{1}$, S G Yasawardene ${ }^{2}$
}

\begin{abstract}
Introduction Although the local inflammatory reactions are known to be regulated through cholinergic antiinflammatory pathways, the exact subtypes of nicotinic acetylcholine receptors involved in neuroimmune modulation are not well identified.
\end{abstract}

Objectives Immunohistochemical localisation of $\alpha 1$ subunit of nicotinic acetylcholine receptors $(\alpha 1 \mathrm{nAChR})$ in sites of localised inflammation induced by injecting turpentine to the hind limbs of Balb/C mice.

Methods Localised inflammation and subsequent development of sterile abscesses was induced by injecting sterile turpentine subcutaneously into thighs of Balb/C mice. Sterile saline was used in the control.. Skin and muscle tissues of inflammatory sites were recovered from the animals after 48 hours and were stained with hematoxylin and eosin. Indirect immunohistochemistry was done using anti- $\alpha 1 \mathrm{nAChR}$ as the primary antibody and biotinylated anti-rat IgG as the secondary antibody. Labeled streptavidin biotin (LSAB) technique was used with diaminobenzedene to detect the immunoreactivity (IR). Intensity of immunostaining was determined based upon a score of $0-3+$ by qualitative computerised image analysis using FSX 100 Olympus microscope.

Results $\mathrm{H}$ and $\mathrm{E}$ stained slides showed polymorphonuclear leukocytes (PNL) infiltration at the abscess sites while the saline injected control tissue sections did not show PNL infiltration. A 2+ immunoreactivity (IR) of $\alpha 1 \mathrm{nAChRs}$ was visible at peripheral zones of sterile abscesses where PNL infiltrations were high while the central area with necrotic tissue did not show IR. A subcutaneous lymph node found within the inflammatory region expressed IR of $\alpha 1 \mathrm{nAChR}$ in its capsular sinuses, subcapsular sinuses and trabecular regions.

Conclusions The findings suggest the possible role of controlling localised inflammatory response by parasympathetic cholinergic nerves through $\alpha 1 \mathrm{nAChRs}$ of inflammation sites.

Ceylon Medical Journal 2015; 60: 143-147

\section{Introduction}

The central nervous system is known to interact with the immune system through the autonomic nervous system and modify immune responses. Though the sympathetic system is the main component which controls the functions of lymphoid tissue, recent evidence shows significant influence by the cholinergic nervous system as well $[1,2]$. Accordingly cholinergic anti-inflammatory mechanisms can inhibit the activation of macrophages and release of cytokines [2].

The cholinergic system, which uses acetylcholine as a neurotransmitter, is one of the excitatory pathways of the central nervous system [2]. Acetylcholine and multiple nicotinic acetylcholine receptor (nAChR) subunits are present on many cell types including endothelial cells and cells of the immune system [3, 4]. Thymocytes, thymic epithelial and myoid cells of immune organs express nAChRs on their cell surface [5]. Peripheral T cells express an unusual profile of muscle type nicotinic subunits, but their nAChR expression has not been identified [6]. In addition, expression of mRNA of $\alpha 5, \alpha 9, \alpha 10, \beta 1, \beta 2, \beta 4 \mathrm{nAChR}$ subunits in the freshly isolated CD4 and CD8 T cells have been reported [7]. Gene expression of $\alpha 1, \alpha 7$ and $\alpha 10$ nAChRs also has been shown in mRNAs of primary human macrophages isolated from blood mononuclear cells [8].

Majority of the evidence shows the expression of $\alpha 7 \mathrm{nAChRs}$ on monocytes and macrophages. [3]. $\alpha 7 \mathrm{nAChR}$ is involved in the anti-inflammatory pathway [8]. Similarly, several studies show the crucial role of $\alpha 7 \mathrm{nAChR}$ in the inhibition of excessive inflammation of many organs in the neuroimmune network [9, 10]. But the anatomical distribution of other nAChRs or their functional effects has not been studied.

A recent study shows that the parasympathetic cholinergic innervations are found predominantly in lymph nodes and spleen parenchyma in the supporting framework of reticulin fibres and consists mainly of $\alpha 1 \mathrm{nAChRs}$ with minimum of $\alpha 7 \mathrm{nAChR}$ in $\mathrm{T}$ cell and macrophage abundant regions of these tissues [11].

${ }^{1}$ Department of Human Biology, Faculty of Health-Care Sciences, Eastern University of Sri Lanka and ${ }^{2}$ Department of Anatomy, Faculty of Medical Sciences, University of Sri Jayewardenepura, Sri Lanka.

Correspondence: SGY, e-mail: <surangiy@hotmail.com>. Received 5 November and revised version accepted 2 October 2015. October 2015. and reproduction in any medium, provided the original author and source are credited. 
The $\alpha 1$ subunit of the $\mathrm{nAChR}$ is described as potential $\alpha$-bungarotoxin-binding receptor in mammalian cells and experimental findings indicate the importance of these receptors in the inhibition of TNF synthesis in vitro by acetylcholine [8]. Studies are sparse regarding the distribution and functional role of $\alpha 1$ subunit of the $\mathrm{nAChR}$ at the site of inflammation.

The aim of our study was to investigate the distribution of $\alpha 1$ subunit of nAChRs in the sites of local inflammation induced by sterile turpentine injection [12]. In mice, it induces the formation of discrete aseptic abscesses without detectable injury to other tissues [12]. Findings of our study would provide the anatomical basis to investigate the role of $\alpha \mathrm{nAChRs}$ on the localised inflammatory response.

\section{Methods}

Balb/C mice (male, $\mathrm{n}=3$ ) aged $7-8$ weeks were purchased from Medical Research Institute and were housed individually in filter-top plastic cages and handled according to WHO guidelines for animal handling.

Sterile tissue damage (localised inflammation) was induced with commercial grade pyrogen free sterile turpentine filtered through $0.2 \mu \mathrm{m}$ pore size sterile filters (Merck Millipore, Germany) to remove all microbes. Thirty micro liters $(30 \mu 1)$ of pure undiluted turpentine oil $(100 \%)$ was injected subcutaneously into both hind limbs of lightly anaesthetised (inhaled dimethyl ether) $\mathrm{Balb} / \mathrm{C}$ mice $(\mathrm{n}=2)$. Injection was done with a $1 \mathrm{ml}$ insulin syringe fitted with a $291 / 2$ gauge needle. The experiment was performed in two animals. Pyrogen free sterile saline was used as the control injection in one $\mathrm{Balb} / \mathrm{C}$ mouse.

The abscess formation was monitored in 12 hour intervals in two groups. After 48 hours, some visible abscesses were localised in the dorsal surface of the hind limbs of the turpentine injected animals. The mice were killed after 48 hours.

The skin and muscle tissues were carefully recovered from the inflammatory site and were immediately fixed in $10 \%$ formaline saline. The tissues were processed for preparation of hematoxylin and eosin ( $\mathrm{H}$ and $\mathrm{E})$ slides. The slides were observed under light microscope for cellular changes of inflammation and photomicrographs of different magnifications were taken digitally with FSX100 (Olympus, USA).

Tissue sections of $4 \mu \mathrm{m}$ thickness were processed for indirect immunohistochemistry (IHC). Citrate buffer $(\mathrm{pH}=6)$ was used for heat induced antigen retrieval, and slides were incubated in 3\% hydrogen peroxide to inactivate the endogenous peroxidases. After washing in $0.1 \mathrm{M}$ phosphate buffered saline $(\mathrm{pH}=7.4)$ the sections were exposed to $5 \%$ bovine serum albumin (BSA) in $0.1 \mathrm{M}$ PBS prior to addition of the primary antibody. The tissues were incubated in a humid atmosphere at $4^{\circ} \mathrm{C}$ for $18-20$ hours with monoclonal antisera raised in rats against $\alpha 1$ subunit of $n A C h R$ (at dilution of 1:3000) (Sigma Aldrich). The antibody has been produced using denatured nicotinic acetylcholine receptors from the electric eel electrophorus as the immunogen. It recognizes an epitope with the sequence 371-386 of the $\alpha 1$ subunit of muscle nAChR [14].

After rinsing, the sections were incubated for 30 minutes in biotinylated anti-rat IgG (Sigma Aldrich) at 1:750 dilutions. The Labelled Streptavidin Biotin (LSAB) technique was used; with diamino benzedene (DAB) as chromogen to detect the receptors by the development of brown colour and counterstained with Mayers' haematoxylin. Skeletal muscle was processed for IHC as positive controls. All antibodies and enzymes were diluted in PBS containing $1 \%$ BSA.

Overall fields in the slide of different immune tissues were observed for the immunoreactivity. Different subcellular compartments in several x400 magnification fields in both IR and non-IR cells were counted and the rough the percentage of IR cells was recorded. Both the intensity of the immunoreactivity and the number of immunoreactive cells were taken into consideration. The numbers of IR cells were counted in several fields of a single slide of immune tissue and average number of IR cells was calculated. The intensity of immunostaining was determined based upon a score of 0 (No staining), $1+$ (focal staining/ less than $30 \%$ of IR cells), $2+$ (focal to diffuse/moderate staining, 30\% $-60 \%$ cells), $3+$ (Strong staining, $61-100 \%$ of cells [15].

Approval was granted from the Ethics Review Committee of Faculty of Medical Sciences, University of Sri Jayewardenepura for the animal experiments and immune tissue isolation.

\section{Results}

\section{Histopathology of sterile abscesses}

On macroscopic examination (after48 hours) swelling was visible and the abscesses had formed in the sterile turpentine injected sites of the hind limb of the $\mathrm{Balb} / \mathrm{C}$ mice. In the control Balb/C mice there were no visible changes in the sites of sterile saline injection. The sterile saline injection did not cause any significant histological changes in the site of control animals [Plate 1(a)]. The micro-structural features were similar to healthy tissue.

The sterile turpentine injection caused a localised inflammation in the skin, subcutaneous tissue and deep skeletal tissues. The $\mathrm{H}$ and $\mathrm{E}$ stained abscess tissue sections with localised inflammation exhibited a large accumulation of PNL near the site of turpentine injection in the hind leg of Balb/C mice [Plate 1(b)]. The centre of the abscess had large necrotic tissue elements such as fibrin, keratin squames, degenerating PNL, macrophages and serous fluid and it was rimmed by surrounding zone of active PNL, lymphocytes and macrophages. The PNL, 

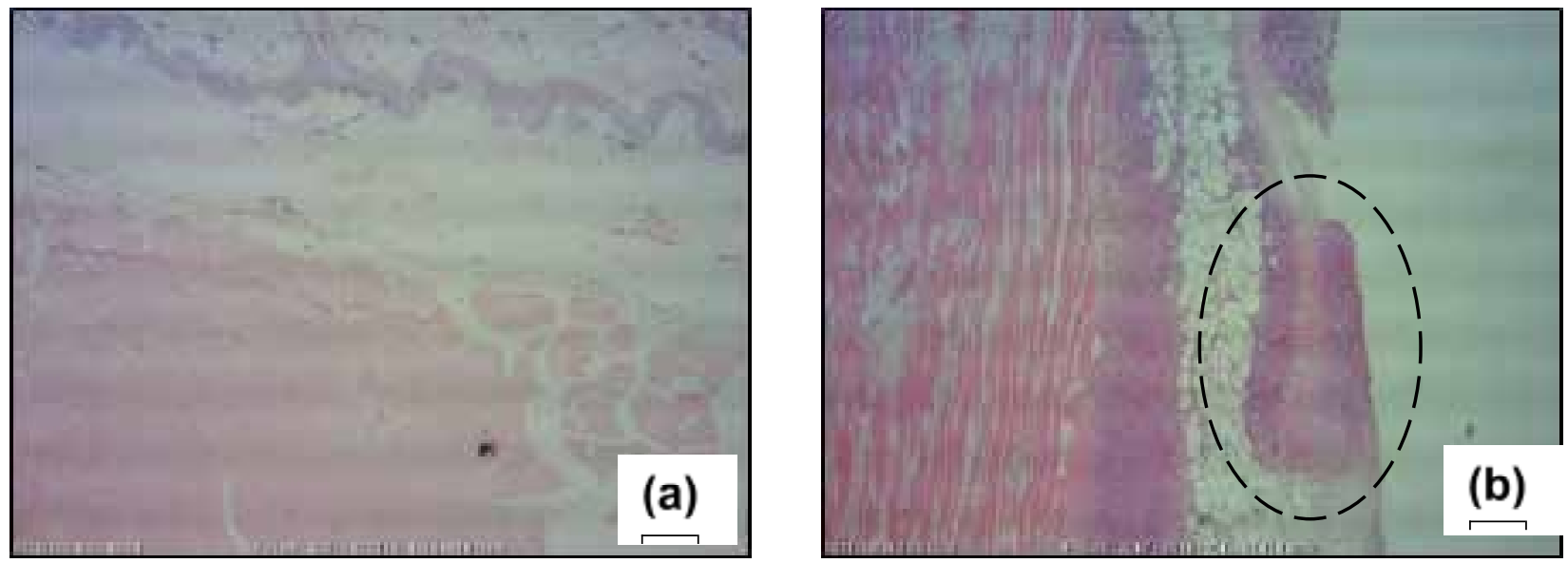

Plate 1. Abscess tissue (H \& E stain)

(a) Dermis of the skin and the subcutaneous tissue of control Balb/C mice, bar $=45 \mu \mathrm{m}$

(b) Subcutaneous tissue of the thigh of Balb/C showing the abscess formation, bar $=45 \mu \mathrm{m}$
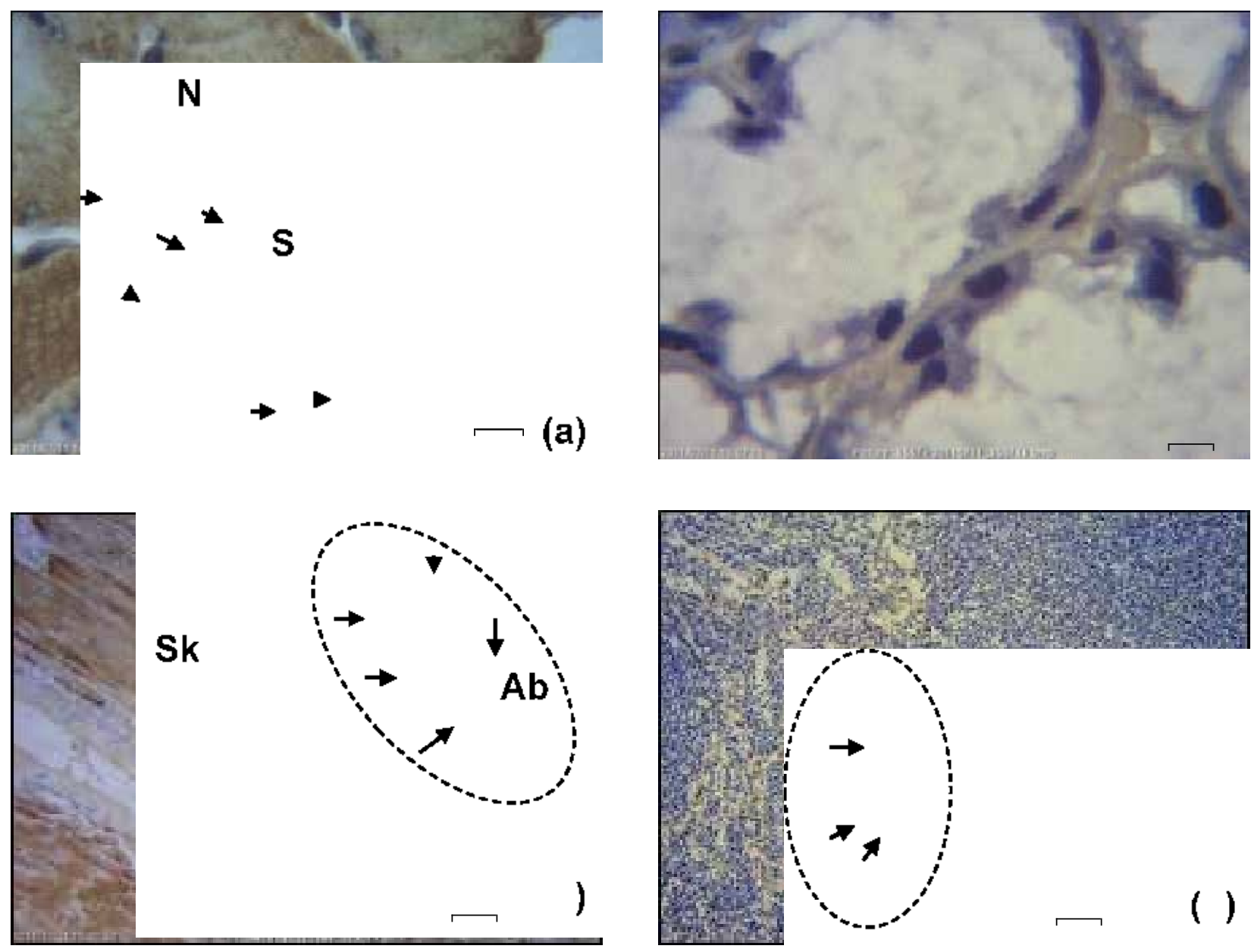

\section{Plate 2. Abscess and subcutaneous lymph node, IHC of $\alpha 1 \mathrm{nAChR}$}

(a) Skeletal muscle of Balb/C tongue, $\alpha \operatorname{lnAChR}$ positive, $\mathbf{S}$ - striations, $\mathrm{N}$-nucleus, $b a r=15 \mu \mathrm{m}$

(b) Lingual salivary gland of Balb/C mice, $\alpha 1 \mathrm{nAChR}$ negative, G- glandular tissue, bar $=10 \mu \mathrm{m}$

(c) Abscess tissue and related tissues, bar $=102 \mu \mathrm{m}$

(d) Subcutaneous lymph node showing $\alpha 1 \mathrm{nAChR}$ positive IR, bar $=20 \mu \mathrm{m}$ 
lymphocytes and macrophages were scattered in between the skeletal muscle tissue and prominent lymph nodes were found in the vicinity of the injected sites.

\section{Immunohistochemistry of sterile abscesses with $\alpha 1$ AChR antibody}

The positive control showed skeletal muscle tissues of the $\mathrm{Balb} / \mathrm{C}$ mice treated with $\alpha \ln \mathrm{AChR}$ antibody expressing a strong diffuse dark brown colour of the cytoplasm and cytoplasmic membrane. The negative control showed sublingual salivary glands with absence of $\alpha 1 \mathrm{nAChR}$ antibody immunoreactivity [Plate 2(a) and 2(b)]. A 2+IR was visible at peripheral zones of sterile abscesses where PNL infiltrations were high for $\alpha \operatorname{lnAChRs}$ while the central area showed less IR [Plate 2(c)]. The subcutaneous tissue found in the vicinity of the abscess showed scattered IR of $\alpha 1 \mathrm{nAChR}$ antibody. A subcutaneous lymph node associated with the inflammatory region expressed $\alpha 1 \mathrm{nAChR}$ IR in its capsular, subcapsular sinuses and trabeculae regions [Plate 2(d)]. Skeletal muscle tissue found in the inflammatory area expressed $2+\mathrm{IR}$, while the leukocytes found in between the muscle tissue expressed less IR of $\alpha \operatorname{lnAChRs.}$

\section{Discussion}

Sterile turpentine is a known inflammatory agent which stimulates inflammation [16]. Accordingly, injection of sterile turpentine induced localised inflammation in the subcutaneous region of hind thigh of mice. The infiltration of neutrophils and macrophages and the histopathological changes of the inflammatory site in the present experimental study were similar to the reported histopathological changes of local inflammation produced by infectious agents [17]. PNL infiltration was significantly higher in test tissues, while in the control tissue there was no PNL distribution.

Sterile turpentine stimulates inflammation by increasing the level of certain serum glycoproteins and the acute phase reactants in circulation and induces the local synthesis of interleukin-1 $\beta$ and TNF $\alpha[12,16]$. Similarly a marked elevation of levels of the major murine acutephase proteins, serum amyloid A and serum amyloid $\mathrm{P}$ in plasma has been reported after 48 hours of turpentine injection [16]. The previous documented studies promoted us to apply sterile turpentine as the irritant to induce sterile inflammation.

The crucial role of cholinergic anti-inflammatory pathway is exerted by potential inhibitory control of inflammation $[9,10,19]$. Neural regulation of acute localised inflammation is by the cholinergic and antiinflammatory pathway known as the "inflammatory reflex". Inflammatory stimuli activate afferent pathways within autonomic nerves like the baro reflex. Relaying in the hypothalamus it elicits an efferent anti-inflammatory response that rapidly prevents the overproduction of inflammatory cytokines. The nervous system integrates the inflammatory response [9]. The autonomic nervous system detects the inflammatory stimuli such as local irritants and produces cytokines. Afferent signals are also thought to be transmitted by autonomic nerves and activate the efferent autonomic nerve signalling and release of $\mathrm{ACh}$ in the vicinity of macrophages. In the cholinergic anti-inflammatory pathway, the efferent arm of the inflammatory reflex is composed of the efferent vagus nerve, the neurotransmitter $\mathrm{ACh}$ and the $\alpha 7$ subunit of nAChR [20]. Based on this concept attempts can be made to treat autoimmune diseases.

In this process acetylcholine can interact with $\alpha 7 \mathrm{nAChRs}$ expressed by macrophages and other cytokineproducing cells, down-regulate proinflammatory cytokine synthesis, and prevent tissue damage [8]. In this study we have shown the expression of $\alpha 1$ anAChRs in sites of local inflammation, suggesting the possible role of these nAChRs in the proposed cholinergic anti-inflammatory pathway. Similar to $\alpha 7$ subtype $\alpha 1 \mathrm{nAChRs}$ expressed in the inflammatory site may inhibit inflammation by suppressing cytokine synthesis.

$\alpha \ln A C h R s$ are known to be $\alpha$-Bungarotoxin binding receptors. These $\alpha$-Bungarotoxin affinity nAChRs are known to produce cross bridges between cholinergic nervous system and immune system. Therefore the findings of the present study would be beneficial in understanding the cholinergic anti-inflammatory pathway.

Although, $\alpha 1 n$ AchRs were identified in the areas of PNL infiltration, even with higher magnification it was difficult to identify the exact cell type expressing the IR. As the abscess site attracted a large amount of macro-phages and PNL, we could assume that $\alpha 1 \mathrm{nAChRs}$ are expressed in the live cells of the peripheral rim of the abscess. This suggests that $\alpha 1$ subtype of nicotinic receptors may play a role in the anti-inflammatory response in localised inflammation. The subcutaneous lymph node associated with the inflammatory region also expressed $\alpha 1 n$ AChR IR in its capsular, subcapsular sinuses and trabeculae regions. This is also suggestive of anticho-linergic control of inflammation.

This study was limited to $\alpha \ln A C h R$ due to the high cost of the primary antibody. Further investigations of the expression and distribution of cholinergic nerves by using the primary antibody markers such as the antivesicular acetylcholine transporter protein antibody and anti-choline acetyl transferase antibody would be useful. The regional lymph nodes draining these local lymph nodes can investigated for the expression of $\alpha 1 \mathrm{nAChRs}$.

In conclusion, the findings confirm the higher expression of $\alpha \ln A C h R s$ at the inflammatory sites. This is suggestive of neuronal control of localised inflammatory response by parasympathetic cholinergic innervation through $\alpha \ln A$ ChRs. 


\section{Conflicts of interests}

There are no conflicts of interest.

\section{References}

1. Bulloch K, Pomerantz W. Autonomic nervous system innervation of thymic-related lymphoid tissue in wild type and nude mice. J Comp Neurol 1984; 228: 57-68.

2. Rand JB. Acetylcholine. Worm Book 2007, doi:10.1895/ wormbook.1.131.1. http://www.wormbook.org (accessed $13^{\text {th }}$ March, 2014).

3. Scott DA, Martin M. Exploitation of the nicotinic antiinflammatory pathway for the treatment of epithelial inflammatory diseases. J Gastroenterol 2006; 12: 7451-9.

4. Saeed RW, Varma S, Peng-Nemeroff T, et al. Cholinergic stimulation blocks endothelial cell activation and leukocyte recruitment during inflammation. $J$ Exp Med 2005; 201; 7 : 1113-23.

5. Kuo Y, Lucero L, Michaels J, De Luca D, Lukas RJ. Differential expression of nicotinic acetylcholine receptor subunits in fetal and neonatal mouse thymus. $\mathrm{J}$ Neuroimmunol 2002; 130: 140-54.

6. Toyabe S, Liai M, Fukuda T, Kawamura et al. Identification of nicotinic acetylcholine receptors on lymphocytes in the periphery as well as thymus in mice. Immunol 1997; 92: 201.

7. Qian J, Galitovskiy V, Chernyavsky AI, Marchenko S, Grando SA. Plasticity of the murine spleen T-cell cholinergic receptors and their role in in-vitro differentiation of naïve CD4 T cells toward the Th1, Th2 and Th17 lineages. Genes Immunol 2011; 12: 222-30.

8. Wang H, Yu M, Ochani M, et al. Nicotinic acetylcholine receptor $\alpha 7$ subunit is an essential regulator of inflammation. Nature 2003; 421: 384-8.

9. Tracey KJ. The inflammatory reflex. Nature 2002; 420: 853-9.

10. Margot G, Tracey KJ. Immunologic Role of the Cholinergic Anti-Inflammatory Pathway and the Nicotinic Acetylcholine a7 Receptor. Ann N Y Acad Sci 2005; 1062: 209-19.
11. Thayabaran M, and Yasawardene SG. Innervation and the distribution of functional nicotinic acetylcholine receptors in human lymphoid tissues - An immuhistochemical study. Proceedings of Sri Lanka Medical Association $125^{\text {th }}$ International Medical Congress 2012.

12. Coolbar T, Moorkerjea S. Effects of Turpentine-induced Inflammation on the Synthesis of Dolichol-linked Intermediateso f N-Glycosylation and the Phosphorylation of Dolichol by CTP-dependent Dolichol Kinase. J Biol Chem 1981; 256: 9.

13. Pohanka M. Alpha7 Nicotinic Acetylcholine Receptor Is a Target in Pharmacology and Toxicology. Intern. J Mol Sc. 2012; 13: 2219-38.

14. Kozak W and Kozak A. Selected Contribution: Differential role of nitric oxide synthase isoforms in fever of different etiologies: studies using Nosgene-deficient mice. $J$ Appl Phys. 2003; 94: 2534-44.

15. Lindstrom J. Ion Channels, Plenum Press, New York 1996.

16. Schaulder M S, Steffenson T S, Morgan M, et al. Assessment of muscarinic and nicotinic acetylcholine receptors in primitive neuroectodermal tumour/Ewing family of tumour and desmoplastic small round cell tumour: An immunohis-tochemical and Western blot study of tissue microarray and cell lines. Fetal Pediatr Pathol 2008: 27; 83-97.

17. Conner JG, Eckersall PD, Wiseman A, Aitchison TC, Douglas TA. Bovine acute phase response following turpentine injection. Res Vet Sci. 1988; 44: 82-8.

18. Chen, G. Y and Nuñez, G. Sterile inflammation: sensing and reacting to damage. Nat Rev Immunol 2010; 10: 826-37.

19. Tracey KJ. Physiology and immunology of the cholinergic antiinflammatory pathway JClin Investigations 2007 ; 117: 289-96.

20. De Jonge WJ, Ulloa L. The alpha7 nicotinic acetylcholine receptor as a pharmacological target for inflammation. $\mathrm{Br}$ J Pharmacol 2007; 151: 915-29.

21. Rosas-Ballina M, Tracey KJ. Cholinergic control of inflammation. J Intern Med 2009; 265: 663-79. 